Supporting Information

\title{
Effects of CMC Addition on Bacterial Cellulose Production in a Biofilm Reactor and Its Paper Sheets Analysis
}

\author{
Kuan-Chen Cheng, Jeffrey M. Catchmark, and Ali Demirci
}

Results of BC production, and its crystallinity and crystal size with and without CMC addition.

$\mathrm{BC}$ production increased with $\mathrm{CMC}$ concentration and reached stable (max $\sim 13.0 \mathrm{~g} / \mathrm{L}$ ) when $1.5 \sim 2.0 \% \mathrm{CMC}$ was added, which was 1.7 -fold higher than the result obtained from the control culture (Table S1). The crystallinity of BC decreased from 86 to $80 \%$ with the presence of $1.5 \%$ of CMC. The crystallite size of $<200>$ plan also decreased from 5.3 to $4.2 \mathrm{~nm}$ (Table S2).

Table S1. Effects of CMC addition on BC production $(\mathrm{g} / \mathrm{L})$ in PCS biofilm

\begin{tabular}{cccccccc} 
reactor $^{\mathbf{a}}$ & & & & & & & \\
CMC Conc. (\%; w/v) & 0 & 0.2 & 0.5 & 0.8 & 1.0 & 1.5 & 2 \\
\hline BC in suspension & 0 & 0.3 & 0.3 & 0.7 & 3.4 & 11.9 & 12.2 \\
BC on PCS & 7.1 & 7.3 & 8.2 & 9.2 & 8.2 & 0.99 & 0.89 \\
\hline Total BC & 7.1 & 7.6 & 8.5 & 9.9 & 11.6 & 12.8 & 13.1 \\
Suspension BC (\%) & 0 & 3.9 & 3.5 & 7.0 & 41.5 & 92.3 & 93.2 \\
Control culture $^{\mathbf{b}}$ & 3.0 & 4.8 & 6.6 & 7.9 & 8.1 & 8.2 & 8.1 \\
\hline
\end{tabular}

${ }^{\mathrm{a}}$ The results are the average of two duplicates.

${ }^{\mathrm{b}} \mathrm{BC}$ production conducted in a suspension culture without $\mathrm{PCS}$.

${ }^{\mathrm{c}}$ Suspension $\mathrm{BC}(\%)=(\mathrm{BC}$ in suspension/ Total $\mathrm{BC}) * 100$ 
Table S2. Results of crystallinity and crystal size of BC from PCS biofilm reactor.

\begin{tabular}{ccc}
\hline CMC addition (\%) & $\begin{array}{c}\text { Crystallinity } \\
\mathbf{( \% )}\end{array}$ & $\begin{array}{c}\text { Crystallite size of }<\mathbf{2 0 0}> \\
(\mathbf{n m})\end{array}$ \\
\hline $\mathbf{0}$ & $86.2 \pm 0.6^{\mathrm{a}}$ & $5.3 \pm 0.3^{\mathrm{a}}$ \\
$\mathbf{1 . 5}$ & $80.3 \pm 0.5^{\mathrm{b}}$ & $4.2 \pm 0.2^{\mathrm{b}}$ \\
\hline
\end{tabular}

Values (in the same column) not marked by the same letter are significantly different ( $p \leqq 0.05 ; \mathrm{n}=3$ ). 